\title{
An exploration of individual, social and material factors influencing water pollution mitigation behaviours within the farming community
}

\begin{abstract}
Diffuse pollution of watercourses from agriculture represents a complex and persistent environmental problem in the UK. This paper provides insights into why UK policy interventions have had limited success to date, drawing on the disciplines of psychology, sociology and behavioural economics to more thoroughly understand farmer attitudes and behaviours towards pollution mitigation. Our analysis is based on eliciting the opinions of commercial farmers through a series of surveys and discussion groups in three catchments: the grassland dominated River Eden catchment; the arable dominated River Wensum catchment and the mixed farming area of the Hampshire River Avon catchment. Results strongly suggest that a fundamental shift in identities, normative behavioural beliefs and social norms is required within the farming community before mitigation behaviours become embedded. Simply offering financial incentives or imposing regulatory penalties is unlikely to achieve the desired results. Double loop learning has the potential to enable farmers to migrate from a productivist to a multifunctional outlook where pollution mitigation becomes internalised within a farm management system. Expert farm advisors will be required to facilitate this process.
\end{abstract}

Keywords: Diffuse, Water, Pollution, Agriculture, Policy, Behaviours

\section{Introduction}

As in many parts of the world, the quality of both surface and ground waters remains a major policy concern in the UK (McGonigle et al., 2012; Wang et al., 2016). Degradation of water quality is by no means solely a result of negative externalities associated with the farmed landscape; with recent developments in source apportionment science revealing that pollutant loads originate from multiple sources situated in both rural and urban locations (Comber et al., 2013; Zhang et al., 2014). However, whilst considerable variation exists both within and between river catchments, pollution from agricultural land continues to represent a wide-scale and persistent problem in most regions of the UK (Defra, 2015). In common with many other countries, the response from government has been to implement a policy mix of regulations, financial incentives and advisory programmes designed to encourage the uptake of mitigation measures by individual land managers on their respective holdings (McGonigle et al., 2014). Unfortunately, the evidence to date suggests that the effectiveness of the policy response in the UK has been limited. The House of Commons suggests that fewer than $40 \%$ of waterbodies currently meet statutory ecological and chemical standards as defined by the EU Water Framework Directive (House of Commons, 2015), whilst other scientists point to a much larger challenge to generate appropriate conditions (Durand et al., 2011; Johnes et al., 2007).

This paper attempts to provide insights into why UK policy interventions have had limited success to date, drawing on the disciplines of psychology, sociology and behavioural economics to examine why farmers decide whether to adopt mitigation activity capable of combating diffuse water pollution from agriculture (DWPA). Numerous studies have identified financial considerations as being important in determining mitigation behaviour (e.g Mills et al., 2013; Siebert et al., 2006) but the assumption of profit maximisation as the overriding behavioural driver has been questioned for some time (Kahneman, 2003; Gintis, 2000). With this in mind, we begin by describing a socio-psychological theoretical framework incorporating individual, social and material factors considered important diagnostic components within the field of understanding human behaviour. There follows a synthesis of scholarly work salient to the topic of pro-environmental behaviours within the farming sector, the aim 
being to populate the theoretical framework with empirical analysis specifically relevant to agri-environmental policy. We then present findings from primary qualitative and quantitative attitudinal research undertaken with farmers in three agricultural catchments to explore further behavioural drivers specifically related to the uptake of DWPA mitigation measures. Following a discussion of the research findings, the paper concludes with some suggested improvements in the way agri-environmental policy targeting water quality improvement is rolled out in the future.

\section{Human behaviour theories}

Many behavioural theories have been created over the years (Coleman, 2015) with a recent and very useful encyclopaedia of 86 behavioural theories provided by Michie et al. (2014). Some of these theories have been developed in an attempt to explain specific behaviours whilst others have sought to provide a framework by which a broad range of behaviours might be explained. By far the most common example of the later type is the Theory of Reasoned Action (Ajzen and Fishbein, 1980) and its successor the Theory of Planned Behaviour (Ajzen, 1991) which have been applied within sectors ranging from health and wellbeing to transport, education and notably agriculture. An examination of the various theories reveals that either explicitly or implicitly, many share a core set of common factors considered important variables determining human behaviour; albeit particular theories sometime use different nomenclature to define the same variables. Additional bespoke variables appear in specific theories, a product of the discipline from which the theory is created together with the nature of the behaviour the theory is attempting to predict. In an effort to bring the various factors together in one space, we refer to Darnton and Evans' (2014) Individual - Social - Material (ISM) model, originally developed for the Scottish Government to assist in the prediction and shaping of behaviours relevant to sustainable development goals.

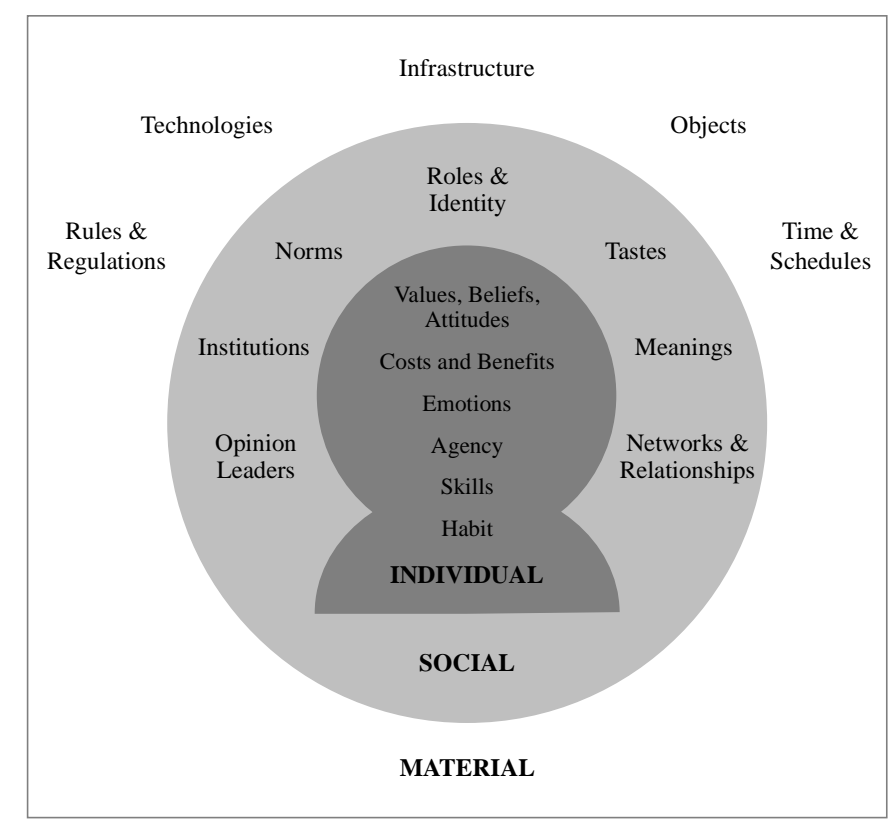

Figure 1. Schematic diagram of the Individual - Social- Material (ISM) model. Sourced: Darnton and Evans, 2014

As depicted in Figure 1, the ISM model identifies a variety of factors that influence human behaviour and places them into: (1) the individual context which includes factors internal to the individual influencing choices and behaviours; (2) the social context which comprise societal influences on the individual, and; (3) the material context highlighting factors beyond the individual's control but which can constrain or facilitate behaviour. Given that the ISM framework incorporates several disciplinary understandings of how human beings behave, Darnton and Evans acknowledge this may cause tension amongst 'theoretical purists'. However, we suggest the model provides an overarching checklist of factors for those who wish to adopt a multidisciplinary approach to behavioural research. Importantly within the context of this paper, we believe an analysis framework based on individual, social and material contexts is well suited to the study of farmer behaviours. 


\section{Pro-environmental behavioural research within the farming community}

A review of the literature reveals there are many studies providing insight into pro-environmental farmer behaviours covering many of the items listed within the ICM schematic outlined above. Extensive reviews can be found in Dwyer et al. (2007), Prokopy et al. (2008) and Mills et al. (2013) with a recent qualitative meta-analysis by Lastra-Bravo et al. (2015).

It is also apparent from the literature that with a few exceptions (e.g Lowe et al, 1997; Handley, 1990) existing research has tended to explore factors influencing the uptake of environmental management options in the round, not measures specifically related to water pollution mitigation per se. Nonetheless, the literature provides a number of useful indicators regarding behavioural factors relevant to the water quality mitigation agenda and worthy of further investigation. A review of this learning is now provided, giving context to the presentation and discussion of primary research which follows in subsequent sections. We focus here on five socio-psychological factors encountered regularly within the farming literature which translate directly to content in the ICM model described above (Figure.1): identities; behavioural beliefs; agency; networks and relationships; and social norms. The order in which these are addressed is intended to mirror the categorisation of factors depicted in Darnton and Evans' model i.e moving outwards from internal factors (the individual context) to the external world (social context). It is evident from the literature that academic enquiry has not tended to focus on factors within the material context. However, whilst agency is placed within the individual context in the ICM model, a discussion by Fish (2014) makes a distinction between an individual's belief that a behaviour can be performed and the 'wider structures' (i.e. material factors) that can impede or limit the behaviour from ultimately being executed. An outline of these wider structures is included within the synthesis on agency in this paper.

It should also be noted that culture is not explicitly included as a separate item within Darnton and Evans' model and hence within our subsequent analysis which - at first glance - might be regarded as a shortcoming given the extensive role cultural values and cultural capital have been shown to play in determining farming behaviours (Burton et al., 2008; Morris and Evans, 2004). However, cultural influences are explored implicitly within our consideration of both identities and social norms and are central to our discussion of the need for a shift in focus within the farming community towards a more multifunctional mindset.

\subsection{Identities}

Identities can be described as providing an individual with a 'frame of reference' for interpreting the appropriateness or otherwise of a given behaviour (Burke and Reitzes, 1981). There is significant evidence from researchers applying a social psychology approach to agri-environmental decision making (Burton and Wilson, 2006) that identities are influential determinants of farming behaviour. In particular when considering uptake of environmental measures, it is broadly reported in the literature that many members of the farming community hold a strong productivist identity where self-respect is derived first and foremost from the production of food (Chouinard et al., 2008; Herndl et al., 2011). A strong production mentality does not preclude the delivery of environmental outcomes and it is possible for farmers to have both strong production and environmental objectives (Small et al., 2016). However, where the promotion of the environmental agenda is seen to challenge productivity goals, this is likely to be met with resistance. On this basis, it is argued that a move towards a more multi-functional view of land use where non-provisioning ecosystem services such as clean water gain in priority is likely to be difficult (Burton and Wilson, 2006) .

As indicated within the theoretical framework outlined in Figure 1, identities are socially constructed. Through the development of identity theory (Stryker and Burke, 2000; Burke and Stets, 2009; Stets and Carter, 2011), it is suggested that identities are shaped by an individual's role in society, the social networks they interact with and the positions they occupy within a given social network or institutional setting (Burke and Stets, 2009). In keeping with other behavioural drivers such as normative beliefs, farmer identities are, therefore, influenced through their interaction with others. The corollary of this, and of importance to policy makers, is that identities have the potential to change if an individual's social environment is dynamic rather than constant. There is considerable empirical research to support this position. Coughenour (2003) found that access to new networks, ideas and scientific innovation could help farmers construct new identities based on conservation farming. Working with farmers in the 
US Cornbelt, McGuire (2013) observed that activation of farmers conservationist identities in a group setting led to a moderation in profit self-interest and a willingness to adopt pro-environmental practices. It appears that a method of enabling reflection and evaluation of activity is important. McGuire offers an interesting proposition that feedback loops, for example performance based environmental management systems, may serve as a catalyst for reconstructing farmer identities and the notion of the good farmer. This issue is returned to in detail later in this paper.

\subsection{Behavioural Beliefs}

As described by Azjen (1991), behavioural beliefs represent a subjective probability that a given behaviour will produce a certain outcome, positive or negative. As such, they determine an individual's attitude towards the behaviour. Individual behavioural beliefs about the likely outcomes of undertaking pro-environmental activity have been identified as a strong predictor of farmer behaviours. Fielding et al. (2005) examined how behavioural beliefs influence intentions to adopt riparian zone management and found strong intenders have far greater faith in the environmental benefits of riparian management and pay less attention to the costs relative to weak intenders. The authors concluded that efforts need to be invested in promoting the benefits of action. Similarly, a study of landowner willingness to participate in a filter strip programme led Yeboah et al. (2015) to conclude there is a correlation between likely participation and perceived water quality improvements.

Given the importance of behavioural beliefs in determining activity, those interested in pro-environmental mitigation measure adoption by farmers have sought to assess the factors influencing their formation. In particular, persuasion theories have been developed to look at how behavioural beliefs underlying attitudes can be influenced through provision of information interventions (Pretty et al, 1992). As outlined by Blackstock et al. (2010), the evidence from empirical research suggests information source characteristics, message characteristics and the motivation of farmers to process information are the key components likely to determine a change in behavioural beliefs. Regarding source and message characteristics, a large literature exists surrounding a need for extension providers to establish familiarity with farming communities which, in turn, builds trust; a vital prerequisite for farmers taking on board and believing new information (Saylor Mase et al., 2015; Ferretti, 2007; Lidskog, 1996). In terms of motivation to process information about mitigation options, Blackstock et al (2010) note that many farmers have low motivation because they have not been convinced there is a need for them to change behaviour (MaCgegor and Warren, 2006). Practitioner experience in the UK (Inman, 2011) strongly indicates that farmers are far from clear whether a case exists for action.

\subsection{Agency}

The concept of agency - the ability to perform a behaviour - is integral to many behaviour models and is considered by psychologists to be a major factor shaping behaviour. As highlighted earlier, a distinction should be made between an individual's internal belief that a behaviour can be performed and structural (material) factors that may help or hinder the behaviour from being implemented (Fish, 2014).

Relevant studies (e.g Price and Leviston, 2014) have concluded that having a sense of control over events and outcomes is a key predictor in determining whether an activity will be performed by farmers. Reasons for lack of control appear varied. Evidence from the literature (e.g. Ingram, 2008) suggests that whilst some farmers hold FACTS (Fertiliser Advisors Certification and Training Scheme) and BASIS qualifications and are well versed in technical topics such as soil nitrogen dynamics, many farmers do not possess such knowledge. Regarding nutrient management, for example, many farmers still do not undertake any form of nutrient budgeting and they continue to perceive their manures as a waste product rather than a valuable source of nutrients. A firm grasp of soil structure management is also thought to be lacking by many farmers. Farm advisors interviewed by Ingram (2008) were of the view many farmers do not have a sufficient understanding of how to examine their soils to determine compaction levels and possible alleviation measures. Reducing compaction, thereby increasing rain infiltration, can significantly reduce run-off of pollutants to watercourses. Discussions with contemporary farm advisors strongly suggests that the digging of soil pits and accurate interpretation of findings is not a skill set possessed by many members of the farming community.

In addition to lack of skills, researchers have identified structural barriers that negatively impact on agency levels. For example, security of tenure has been cited as a key variable, an obvious problem being a tenant's reluctance to 
invest in farm environmental infrastructure (e.g. soil health, nutrient management facilities) when the benefits of this investment may not be able to be realised should their tenancy agreement be terminated (Inman, 2011). On a general level, there is an overarching trend in the UK to move from multi-generational tenancies towards shorter term (5-10 year) Farm Business Tenancies.

Possibly one of the most interesting insights to come from this literature is that financial constraints do not always appear to be the most important factor determining perceived control levels (Lynne et al, 1995). For example, in their analysis of landholder intentions to adopt riparian zone management activities, Fielding et al (2005) identified no difference in reported financial constraints between strong and weak intenders. However, larger infrastructure investments are more likely to be affected by confidence in financial security. Fish (2014) refers to the existence of debt as a potential negative influence on agency and this was also identified by ADAS (2012) in a study on the uptake of climate change mitigation options by farmers. Here, farmers regarded the availability (or lack) of finance as a crucial factor in the adoption of capital intensive interventions such as precision farming technology or slurry store expansion.

\section{$3.4 \quad$ Networks and Relationships}

As indicated within the social context depicted in Darnton and Evans' ICM Model (Figure 1), networks and relationships can have an influence on human behaviour. Within the realm of farmer behaviours, several research studies have identified access to networks as being a significant predictor of environmental practice adoption (Baumgart-Getz et al., 2012). In particular, if an environmental practice can be demonstrated by someone within a farmer's social network, it is more likely that uptake will occur (Pannell et al., 2006). This has led researchers to postulate that the more members within a decision maker's network, the greater will be the likely exposure to new ideas, techniques and ways of thinking (Small et al., 2016). However, whilst the analysis suggests it is important for farmers to be embedded in some form of network, exactly what type of network results in greater or lesser adoption of new practices is far less clear. A normative view that innovative farmers have access to a wide external network and knowledge base (Padel, 2001) has been questioned in recent years. For example, research by Compagnone (2015) using Social Network Analysis demonstrated that innovation can also be the product of more localised relational networks based around a close geographical proximity. Some networks can be characterised as being populated by dense clusters of individuals with close social bonds whilst other networks comprise members with a looser affiliation incorporating links to a broader array of external contacts (Crowe, 2007; Baldassarri and Diani, 2007). Closely connected individuals may demonstrate a cohesion more conducive to enabling new ideas to be processed and accepted than weaker structures (Crowe, 2007). However, acceptance of new ideas may prove limited where social norms within farming communities favouring a status quo act as a barrier to change; and social norms are likely to be far stronger in densely linked networks than more dispersed structures.

\subsection{Social Norms}

Social norms can be defined as rules developed by a group of people that govern how individuals within that group should behave. Norms change according to context and may evolve over time. They feature in numerous behaviour theories and are considered a very important influence on human activity. In a farming context, norms are important because 'farmers understand their action to be 'right' or 'wrong' given wider expectations, and this may oblige them to act in a particular way' (Fish, 2014). Regarding pro-environmental farming behaviours, research has identified a positive relationship between intention to act and motivations to comply with the perceived wishes of referent groups (Fielding et al., 2005). There is, however, no consensus within the literature regarding who are the key influencers and the proportion of the farming community who feel under some form of obligation to comply with their views. With reference to Ajzen $(1980,1991)$, it is not only important to understand injunctive normative belief strengths which identify how strongly farmers feel certain groups would like them to behave in a certain way. It is also important to understand whether farmers care what these people think. There are potentially a number of sources of influence on farmers including members of the public, conservation groups, supply chain interests and fellow farmers. However, little research has sought to establish the relative strength of these groups. Carr (1988) found that the conservation community has little social influence on farmers; with family, neighbours, the National Farmers Union and the farming press having greater traction. In a culture heavily dominated by productivist values, it is perhaps not 
surprising that farmers are more positive towards the uptake of 'tidy farm' measures that demonstrate economic success (e.g. a new fence) than less tangible signs of 'good farming' such as planting buffer strips (Burton, 2004; Collins et al., 2016). This strongly suggests that the norm within the farming community is heavily weighted towards a focus on food production activities rather than the provision of multiple ecosystem services. To act in contradiction to this mainstream ideology is likely to carry reputational risk (Blackstock et al., 2010).

\section{Behavioural research within the farming community focussed on water pollution mitigation}

There is, therefore, a rich literature on farmer environmental management behaviour which highlights a number of socio-psychological factors likely to be pertinent to a study of DWPA mitigation adoption by the farming community. To provide a more detailed understanding of farmer behaviours within the specific context of DWPA mitigation, we present findings from primary research undertaken with farmers in three catchments in the UK: the grassland dominated River Eden catchment; the arable dominated River Wensum catchment; and the mixed farming area of the Hampshire River Avon catchment. This research has been conducted as part of the Demonstration Test Catchment (DTC) project (McGonigle et al., 2014) undertaken for the UK Department of Environment Food and Rural Affairs (Defra) to assess policy options for combating DWPA and meeting the requirements of the EU Water Framework Directive.

The scope of our research focused on the socio-psychological factors most often encountered within the literature on farmer pro-environmental behaviours and reviewed in the previous section: identities; behavioural beliefs; agency; networks and relationships; and social norms. There are a number of other individual factors outlined in the ISM model such as habit (individual context), institutions (social context) and a range of material considerations which. represent obvious fields of enquiry for future investigation by interested parties.

\section{Method}

\subsection{Scope and research techniques employed}

DWPA measures take a variety of forms from the management of farm infrastructure such as manure management facilities and tracks through to alterations in the management of existing cropping and livestock regimes. Adoption of completely different forms of land use may be implemented. Some measures represent minor changes to the existing status quo whilst others might involve a radical departure from a business as usual scenario. It is likely that a combination of measures targeting the spectrum of risks associated with pollutant sources and delivery pathways from farms to rivers will be needed to deliver the required results. In order to understand the relationship between sociopsychological factors and the adoption of different types of measures, our research design involved eliciting responses to a variety of on-farm measures currently supported by policy instruments and schemes using a three phase approach incorporating both quantitative and qualitative methods:

Phase 1 Baseline Survey - This exercise involved either telephone or face-to-face exploratory interviews with 73 farmers across our three study catchments to assess their current and planned uptake of 30 DWPA mitigation measures as defined by Defra's Inventory of Mitigation Methods User Guide (Newell-Price et al., 2011; Cuttle et al., 2016). This initial exercise provided an opportunity to assess relative uptake rates for different measures but the primary purpose was to recruit farmers to take part in a more detailed follow-up attitudinal study.

Phase 2 Follow-up survey - The initial baseline study was followed by a more detailed telephone attitudinal survey to examine the reasons for measure uptake and barriers to adoption. The questionnaire designed for this phase of the research primarily featured the use of 5 point Likert scales (e.g. $5=$ strongly agree, $1=$ strongly disagree) designed to elicit responses to attitudinal statements relevant to the socio-psychological factors identified for investigation within the study. These entries were supplemented with open-ended questions requiring spontaneous responses which were subsequently coded into frequency counts. A total of 66 respondents took part in this follow-up survey.

Phase 3 Establishment of discussion groups - these were convened after the quantitative surveys had been completed both to ground-truth the survey results and further explore emerging themes. The groups also provided an opportunity for the research team to construct a de facto localised farmer network in each study area, enabling observations 
relevant to the investigation of social norm, identity and network relationship dynamics. Each group met intermittently over a 9 month period at a variety of locations. Not all group participants had taken part in the previous survey exercises.

\subsection{Sample}

Farms were selected from a sample frame of leads provided by a selection of organisations engaged with the farming communities within the study areas. Recruitment was undertaken by initial warm-up letter, followed by either telephone or face-to-face contact. Nationally with respect to England and Wales, the DTC study areas capture over $80 \%$ of soil and rainfall combinations and thereby two principal environmental factors driving DWPA. In addition, the study catchments provide a nationally representative population of farms in terms of contrasting farming system types (on the basis of the Defra Robust Farm Type typology; Defra, 2010) and of the current uptake of on-farm mitigation measures for DWPA including those funded by agri-environment schemes.

The sample for the study comprised commercial farmers who derived the majority or all of their incomes from their farm business. Barnes et al (2011) identified that it tends to be the commercial farms that make up what the authors describe as a 'resistor' group. These farmers are often sceptical about the link between farming and pollution and suspicious of the science used to make this association. They are also largely in the anti-regulation camp and have an aversion to prescriptive measures designed to mitigate DWPA problems. Our research team took the view that this less accessible farmer type is a core target group for policy makers (including the research sponsor) and should therefore constitute the population from which the sample was drawn. Given the commercial nature of the selected farms, average farm size for our sample was marginally larger than that for all farms within the study catchments.

No attempt was made to stratify the sample by farm type, size or by farmer demographics such as age, education or social class. Our rationale for this was lack of consensus in the literature regarding correlation between behaviour and standard socio-economic variables. Whilst there are some studies that have identified associations between these variables and farmer behaviour, there are an equal number of studies that have not. To illustrate this point, Knowler and Bradshaw (2007) assessed 31 separate studies on conservation tillage uptake and could not find robust socioeconomic predictors of behaviour.

\subsection{Data analysis and presentation}

All quantitative survey data were analysed using SPSS statistical software (version 23) to produce data tabulations and to determine any statistically significant differences in response data between the three DTC study areas. Given the small sample sizes generated within each study area, it was not possible to identify significant differences. Consequently, the survey data are presented and discussed in aggregate form. Qualitative findings from the discussion groups were recorded by project team researchers for subsequent review using Content Analysis to collate findings into salient themes. The reporting of findings is complemented by verbatim comments made by individual group participants.

\section{Results}

Research results are presented under headings corresponding to the five socio-psychological factors reviewed in the literature: identities; behavioural beliefs; agency; networks and relationships; and social norms.

\subsection{Identities}

Both the attitudinal survey and discussion group outputs supported the view outlined in existing literature that farmers identify themselves first and foremost as producers of food. As outlined in Table 1, responses to the identity statement demonstrate a weighting in favour of food production as opposed to environmental management orientation; with only $23 \%$ of respondents answering 'disagree' or 'strongly disagree'. 
Table 1. Response to attitude statement - 'At the end of the day, I rate a farmer's ability by the quality of crops or livestock produced, not by their skills as an environmental manager'

\begin{tabular}{lc}
\hline & Response profile \\
\hline & \\
Strongly agree & $5 \%$ \\
Agree & $31 \%$ \\
Neither/Nor & $41 \%$ \\
Disagree & $18 \%$ \\
Strongly disagree & $5 \%$ \\
\end{tabular}

Base: All respondents to follow up attitudinal survey

The strength of this identity was described very clearly by discussion group participants on a number of separate occasions:

'All of us here, we've got a passion for producing a lamb, raising a cow or growing a crop which someone will eat. That's why we get up in the morning' (Sheep Farmer, Tenant)

'You've got to produce your cows, your corn, your sheep, your pigs - whatever it is you produce - to the best of your ability so that we can feed the country' (Dairy Farmer, Owner Occupier)

It is not surprising that DWPA measures regarded as representing a challenge to this identity are unlikely to be adopted. This was reflected in the uptake figures for mitigation measures derived from the Phase 1 baseline survey which showed that options involving land use change to produce non-food related outputs are unlikely to gain widespread traction. Discussion group participants were well disposed to measures which they regarded as representing common sense activity aligned to the objectives of improving agricultural production. Measures not serving this aim, particularly land use reversion activity, were characterised as originating from a space outside the farming community with a separate identity. This viewpoint was clearly articulated by one River Avon DTC discussion group member describing changes to a local farm he had known since a child:

'This farm used to be known to everyone as a real gem, a really productive bit of land. Then it got taken over by someone from outside - not a farmer-and completely given over to the environment. I think you could describe this as a complete waste' (Mixed Farmer, Tenant)

\subsection{Behavioural Beliefs}

Within the follow-up survey, respondents were asked specific questions relating to perceived financial and environmental outcomes from a selection of on-farm DWPA measures they had adopted. As outlined in Table 2, with the exception of cover cropping, there was a behavioural belief amongst the majority of respondents that financial benefits will result from the mitigation measures they have adopted. A behavioural belief in financial benefit was linked not just to perceived direct savings, for example the reduced usage of agro-chemical inputs, but also indirect benefits from increased livestock productivity. These were thought to arise from improved animal health and thereby reduced veterinary costs and a reduction in the risk of financial penalties caused by the contravention of current environmental legislation. 
Table 2. Farmer perceptions of financial and environmental outcomes from adopted measures

\begin{tabular}{|c|c|c|c|c|c|}
\hline Measure & $\begin{array}{l}\text { Financial } \\
\text { Outcome }\end{array}$ & & & & $\begin{array}{l}\text { Environmental } \\
\text { Outcome }\end{array}$ \\
\hline & Benefit & Cost & Neutral & Unsure & Mean* \\
\hline Cultivate compacted tillage soils & $94 \%$ & $2 \%$ & $2 \%$ & $2 \%$ & 3.8 \\
\hline Move livestock to avoid poaching & $93 \%$ & $0 \%$ & $7 \%$ & $0 \%$ & 3.7 \\
\hline Loosen compacted soils on grassland & $89 \%$ & $0 \%$ & $0 \%$ & $11 \%$ & 3.6 \\
\hline Exclude livestock from watercourses & $52 \%$ & $19 \%$ & $10 \%$ & $19 \%$ & 4.0 \\
\hline Establish cover crops in Autumn & $47 \%$ & $6 \%$ & $3 \%$ & $44 \%$ & 3.2 \\
\hline
\end{tabular}

*means derived from a perceived scale of environmental improvement from 1-5 where $1=$ 'none at all' and $5=$ ' $a$ great deal'

Base: All respondents to follow up attitudinal survey who had adopted the stated measures

It is also interesting to note that respondents anticipated environmental outcomes from the actions they had taken. This is in keeping with findings from the literature which suggest a positive correlation between perceived environmental benefits and intention to act.

In contrast to the prevailing view in the literature, the attitudinal survey results depicted a situation where respondents did accept a link between farming practice and water pollution. This can be clearly seen in the response profile to the attitudinal statement outlined in Table 3.

Table 3. Response to attitude statement - 'There is a clear link between some farm practices and water pollution'

\begin{tabular}{lc}
\hline & Response profile \\
\hline & \\
Strongly agree & $20 \%$ \\
Agree & $62 \%$ \\
Neither/Nor & $15 \%$ \\
Disagree & $3 \%$ \\
Strongly disagree & $0 \%$ \\
& \\
\hline
\end{tabular}

Base: All respondents to follow up attitudinal survey

Importantly, however, feedback from discussion group participants demonstrated considerable confusion over the scale and severity of the problem caused by the agricultural sector (especially relative to other sectors) and the probability of DWPA interventions making a tangible difference to the situation. It became evident during discussion group meetings that participants had not historically been presented with scientific evidence regarding the chemical and ecological condition of waterbodies in their local catchment areas.

\subsection{Agency}

The research highlighted a number of factors which research participants suggested impacted on their agency to adopt DWPA control measures. Often cited were weather related variables representing a perceived background impediment to mitigation activity being undertaken successfully:

'When you get seven inches of rain falling in a few hours, which seems to happen more often nowadays, there's no soil that can handle that no matter how well it is managed. You can do what you want but you can't control the weather' (Mixed Farmer, Owner Occupier)

"Rainfall - this autumn it rained early and heavily so there's been more poaching of the soil. So I have to put livestock in barns for longer, which I don't like doing because of the risk of respiratory problems, but I had to be flexible this year. The ground's not looking too bad now, but generally it's weather patterns that might interfere with what you would ideally like to do' (Beeffarmer, Owner Occupier)

Lack of time was also a recurring perceived obstacle, both in terms of performing DWPA abatement activity but also in terms of attending briefings or other training fora to learn new skills and techniques. On the topic of skills, discussion group participants were asked to consider whether lack of skills represents a barrier to uptake. Here, 
participants were split equally between those suggesting more advice is required and those feeling they possess the requisite knowledge.

Financial constraints were mentioned by one in five respondents to the attitudinal survey although when asked to list barriers to uptake of DWPA measures spontaneously, the weather featured as highly as financial considerations. Not surprisingly, financial constraints were more often considered a problem for large infrastructure investments such as slurry storage. Lack of access to finance was exacerbated by a feeling of being time poor. For example, discussion group participants noted grants were available for infrastructure investment, most noticeably via the government funded Catchment Sensitive Farming capital grant programme, but it appears the application window for such grants often coincided with the busiest time in the farming calendar.

A widely expressed sentiment returned to on numerous occasions during the discussion groups was a feeling that an underlying lack of profitability exists across all farming sectors; and that this is not the making of the primary producer. Due to perceived market imbalances, farmers considered themselves to be price takers not price makers with very little control over their financial destinies. This, in turn, has led them to 'farm the land harder than is ideal' which they conceded had resulted in increased negative environmental externalities, particularly associated with excess nutrient and soil loss. There is, therefore, a strong sense of financial disempowerment amongst the farming community and a perceived inevitability of environmental damage, which is not conducive to generating enthusiasm for DWPA mitigation activity.

Finally, in keeping with the broader literature on factors affecting farmer agency, both the attitudinal survey and the discussion group findings revealed that tenancy arrangements can have a significant impact on the propensity to engage in DWPA control measures. Most noticeably, tenants are reticent to engage in longer-term initiatives such as soil improvement measures or substantial infrastructure investments where there is a perceived risk they may not fully benefit from such activity.

\subsection{Social Networks}

The scope of the research did not allow for a quantitative analysis of the size and shape of farmer networks existing within the three DTC study areas. However, it was possible to determine from the discussion groups that some participants had noticeably larger networks than others and significant variation existed regarding the frequency of engagement with these networks. Despite the variations, a commonly held view raised during discussion group events was a perceived value in localised networks populated by farmers who had similar farming systems. This finding was echoed by results from the attitudinal survey which suggest farmers would be positively disposed to joining collaborative groups aimed at developing geographically focussed solutions to DWPA problems (see Table 4). In particular, evidence from the research suggests interest in joining groups stems - in part - from a wish to make up a shortfall in social interaction. Structural changes in the industry mean that opportunities for farmers to meet are less frequent than they used to be leading to an increased sense of isolation becoming commonplace.

Table 4. Willingness to engage in local farmer networks

\begin{tabular}{|c|c|c|c|c|}
\hline Definitely & Probably & Not sure & Probably not & Definitely not \\
\hline \multicolumn{5}{|c|}{ Discussion group to develop ways of managing water pollution including undertaking research } \\
\hline $41 \%$ & $38 \%$ & $12 \%$ & $8 \%$ & $2 \%$ \\
\hline \multicolumn{5}{|c|}{$\begin{array}{l}\text { Developing joint Countryside Stewardship* agreements which aim to co-ordinate activity such as buffer stri } \\
\text { establishment across multiple farms }\end{array}$} \\
\hline $32 \%$ & $26 \%$ & $18 \%$ & $17 \%$ & $8 \%$ \\
\hline
\end{tabular}

The notion of peer to peer knowledge exchange received a strong positive response. One research participant mentioned he felt it was crucial to learn from other farmers with shared experience and cited his long-term membership of a local grazing group as an example of a valued opportunity for information exchange. This group 
appears to be highly integrated with levels of trust robust enough to allow the sharing of accounts and other sensitive financial information for the purposes of analysing business efficiencies and exploring future opportunities. In keeping with other research (Carr and Tait, 1990), participants were strongly of the view that farmers prefer to learn from other farmers due to their applied experience and lack of external agenda. This tribal nature was further exemplified by one discussion group participant in the River Wensum who explained how he had felt 'outnumbered' at a recent regional farming conference by land agents, government advisors and representatives from environmental organisations. Another participant expressed his scepticism about external advisors by suggesting they overcomplicate both problems and solutions to justify their existence. Observations from the River Avon discussion group, where an external agri-environmental expert was invited to address the group about the magnitude of soil erosion in the UK, suggest that distrust in untested information sources is high.

\subsection{Social Norms}

Possibly one of the most striking findings from the research in relation to social norms was a strong sense amongst farmers that earning a living from the environment is in some way a less noble occupation than being a producer of food. One River Avon discussion group member summarised this viewpoint clearly when considering future scenarios for his business:

'If I were to get the same money as my neighbour but I'm getting it from the environment whilst he is producing food, I'd feel a fraud. I suppose it's a macho thing us farmers have got in us' (Dairy Farmer, Owner Occupier)

This perceived lack of respect from engaging too prominently with the environmental agenda was mirrored by findings from the attitudinal survey which revealed that the majority of respondents did not seek recognition from their peers for undertaking DWPA mitigation behaviour. As indicated in Table 5, only 24\% of respondents felt they would engage in a control measure on the basis that it would be noticed by other farmers.

Table 5. Response to attitude statement - 'If I'm going to take on a measure, I want it to be something that other farmers will recognise,

\section{Response profile}

$\begin{array}{lr}\text { Strongly agree } & 6 \% \\ \text { Agree } & 18 \% \\ \text { Neither/Nor } & 52 \% \\ \text { Disagree } & 15 \% \\ \text { Strongly disagree } & 9 \%\end{array}$

Base: All respondents to follow up attitudinal survey

When discussing measures to reduce soil compaction, the majority of discussion group members did not feel under significant pressure from their farming neighbours to take action. Collectively, these results strongly indicate that there is not a norm generated within the farming community itself which encourages the proactive adoption of steps to deliver DWPA mitigation outcomes.

Perceptions were mixed regarding public expectations to deliver DWPA mitigation activity, with some discussion group participants beginning to sense water quality issues are reaching the popular consciousness. However, there appeared to be a widely held view that most members of the public have a narrowly focussed interest on animal welfare and aesthetic considerations:

'The public don't care how the land is managed and how food is produced. They are only interested in making sure the countryside doesn't smell (from manure applications). They'll let you know your livestock are not well but that's about it' (Mixed Farmer, Owner Occupier)

Whilst discussion group participants were of the view that, in line with public concerns, food retailers are primarily interested in animal welfare standards, there was a perception that they are now beginning to turn their attentions to 
natural resource management issues. The context here being that some supermarkets are placing an increasing emphasis on soil and water husbandry standards as part of farm assurance accreditation. A primary reason for this is the perceived lobbying efforts of environmental organisations.

\section{Discussion}

As pointed out in the introductory section, the current DWPA mitigation policy mix in the UK of incentives, advice and regulation has not brought about the scale of change needed to meet water quality targets. This section discusses the key learning outcomes derived from our research which offers a socio-psychological perspective on how this situation might be improved going forward.

Based on a review of the various explanatory documents issued to the farming industry by government and its agencies, there appears an underlying assumption that farmers have bought into the DWPA mitigation agenda and that they will proactively engage with, and comply with, instruments designed to bring about the necessary improvements. The reality of the situation, as outlined in the previous sections, is that a significant shift in identities and behavioural beliefs within farming communities is likely to be required before DWPA mitigation behaviour becomes embedded. DWPA measures which represent business-as-usual activities with perceived financial benefits are increasingly being adopted. However more challenging measures, most noticeably land use change, continue to remain contrary to the productivist culture of the majority of farmers where social norms perpetuate an indifference to activities perceived to challenge the primary role as the agricultural producer. Yet it is precisely these more demanding changes which the scenario modelling community suggest will be required to make a substantive improvement to the quality of freshwater ecosystems in many UK catchments (Johnes et al., 2007; Greene et al., 2015; Collins and Zhang., 2016). A succession of incentive payments, most recently packaged into a revised Countryside Stewardship Scheme, have been available to compensate the income foregone by farmers adopting more far reaching DWPA goals. Uptake, however, has remained low (Collins et al., 2016; Collins and Zhang, 2016) reinforcing the message that such measures are not an attractive proposition to their target audience.

The question of how to modify identities and social norms is a central pillar of many theories of change. Emerging from these theories is an increasing consensus for a need to incorporate individuals within a group learning situation based around the use of feedback loops. In particular, the concept of double loop learning (Argyris and Schon, 1996) is now well grounded within the behaviour change literature as being essential to achieving fundamental shifts in behaviour and the creation of new norms. Within double loop learning, the individual initially engages in 'first loop' learning where impacts of a given action are considered and evaluated. Double loop learning occurs where assumptions informing the first loop learning are reviewed and scrutinised resulting in a completely new way of thinking. From this new outlook, new behaviours, norms and identities are embedded within the group undertaking the learning process.

Within the context of changing farmer identities and norms regarding DWPA mitigation activity, a double loop learning process might involve taking farmers through a voyage of discovery whereby the state of water quality parameters is evaluated based on the existing uptake of DWPA measures. An enhanced programme of business-asusual measures is then agreed, implemented and monitored. By undertaking this process, as per the ongoing DTC programme, it is possible to envisage that the farmers will realise the scale of the challenge; and concur that a solution will necessitate fundamental changes in farming systems including land use change. It is this awakening that could lead farmers to think differently about their role in society and the role of the land they manage. This, in turn, might begin a transition from a productivist to a multi-functional norm within the farming community, encouraging farmers to engage more proactively with the incentive packages and advice programmes on offer to them. Burton and Wilson (2006) believe this will take a long time to happen and that policy makers should regard such an ambition as ' $a$ hypothetical goal for the future rather than a contemporary reality'. Nonetheless, there would appear to be a strong argument in favour of trialling such interventions and there are a variety of decision support tools already in place in the UK capable of facilitating such a process.

Assuming initiating double loop learning processes with groups of farmers is a worthwhile exercise, there remains the question of which type of group setting would be most productive and likely to gain the greatest buy-in from farmer participants. The findings from our group discussions strongly indicate that localised networks are most likely to provide a trusted operational base. In particular, discussion group participants suggested the dissemination and 
adoption of DWPA measures may well be best achieved through tapping into local farming discussion groups where they exist and creating them where they are absent. Historically, government policy has not directly supported the formation of farmer discussion groups but there are signs this is beginning to change with the recent introduction of facilitation funds for Countryside Stewardship collaboration. Our research findings suggest this is a direction of travel that should be continued into the medium and long-term and the ongoing DTC programme will continue to underscore such findings.

There is also a question relating to whether an envisaged farmer network or group should be populated exclusively by farmers or whether other stakeholders should be invited to create a 'community of practice' (Watson et al, 2013). There is a school of thought amongst behaviour change practitioners that creation of social pressure from outside influencers may lead to farmers adopting new normative positions. For example, in New Zealand, environmental groups have undertaken considerable negative media campaigning focussed on the water quality impacts of dairy farming (Small et al, 2016). Advocates of citizen science approaches in the UK, involving members of the public monitoring and reporting on the quality of their local waterways, suggest this will lead to greater vigilance in farmer management practices. There is, however, no evidence that such approaches actually result in farmers changing their ways. On the contrary, evidence from our research would suggest farmers do not believe members of the public have sufficient knowledge to make informed decisions on the appropriateness or, otherwise, of farm practices. The corollary of this is that farmers are unlikely to respect public scrutiny and worse still, popular criticism might lead to farmers developing a siege mentality preventing them opening up to the type of double loop learning outlined above. Moving away from public involvement, there is a potential argument in favour of involving processing and retailing elements within the food supply chain in a group learning based process with farmers. Our research suggests farmers are beginning to perceive a direction of travel amongst food retailers towards a greater interest in natural resource management and benchmarking thereof within the farming sector. Unlike their assessment of the public, farmers consider the food supply chain to represent a professional network with whom an informed discussion might be conducted. Their fear at present is that they will be asked to deliver greater levels of environmental husbandry, including DWPA control measures, without financial recompense and without any say. This perception is likely to cause farmers to defend the status quo, preventing a space to develop where new ideas and practices can be considered. By involving the supply chain in a facilitated deliberative discussion with farmers, it may be possible to establish a situation where a positive discussion concerning the sustainability of the food system ensues from which new jointly owned and accepted norms over managing water resources emerge. Darnton (2008) makes reference to the fact that the questioning of assumptions implicit within double loop learning is uncomfortable and quotes Schein's assessment of the inevitable pain involved in the process of learning and change. Given the political and cultural tensions that exist within the food supply chain, enabling such a discourse to happen is likely to be difficult and will require careful consideration and planning to avoid unintentional negative consequences.

Our discussion, thus far, has focussed on changing farmer identities and social norms around the management of DWPA through on-going dialogue within a group setting. However, it is likely that many farmers will not be willing or able to be active participants in such fora. It is envisaged that the diffusion of messages and norms emanating from farmer groups would reach a broader farming audience; but which policy mechanisms can be leveraged to communicate directly with a broader pool of farmers at an individual level? With reference to Darnton's ICM Model (Figure 1), this means influencing the individual context. It is here where persuasion theories designed to shape individual behavioural beliefs through the provision of information have salience (Pretty et al, 1992). As pointed out in our review of the literature, socio-psychological research has shown there is a correlation between whether farmers believe a practice will lead to positive environmental outcomes and their intention to act. Our subsequent primary research with farmers revealed that beliefs relating to the efficacy of the DWPA measures are generally positive. There would, therefore, appear to be a strong argument for the roll out and promotion of localised case studies and demonstration sites, facilitated by trusted extension workers working closely with innovative and respected farmers (Amber Saylor Mase, 2015). The use of demonstration is not a novel concept and has been widely applied by agricultural extension workers world-wide in relation to crop and animal productivity scenarios. Evidence from our research is that systematic and broad scale use of case studies and demonstration sites to illustrate working examples of DWPA in action is embryonic in the UK (e.g. via the DTC and Catchment Sensitive Farming programmes) but is growing significantly in momentum. Farmers also need to hold a behavioural belief that the scale and severity of water pollution in their locality is such that it represents a real problem requiring action. It was revealing that many 
farmers attending the discussion groups had not previously been exposed to such data in a format they could readily interpret and understand. This suggests much greater effort is required by public authorities to undertake appropriate dissemination of data through a report card format or similar (Smith and Hiscock, 2009).

It became apparent that in addition to issues surrounding norms, identities and behavioural beliefs, there are significant barriers to the uptake of DWPA measures which relate to a lack of agency within the farming community. From a behaviour change perspective, it would appear that finding solutions to these barriers represents a major policy challenge requiring significant government intervention. In the first instance, our research suggests a large number of farmers believe they require further advice in DWPA management techniques indicating that a skills deficit exists. What makes plugging the skills gap difficult is that research respondents reported a strong preference for one-to-one advice delivered on farm. An aversion to group based training and advice is based on a deeply felt premise that this format is incapable of being tailored to individual farm-specific circumstances. Given successive governments in the UK have not supported a one-to-one advice model on account of cost, this represents a policy conundrum with no clear likelihood of resolution.

Another agency based barrier to adopting and implementing DWPA control measures is a perceived lack of available time. A steady reduction in farm labour units has been a feature of the UK agricultural scene for decades (Burgess and Morris, 2009) with this trend not likely to change in the foreseeable future. Given this structural shift in the sector, it is hard to see how a lack of agency created by time poverty can be overcome. Over the long-term, an increased amalgamation of small and medium farms into larger units may provide an increase in management capacity but an argument that larger units deliver better environmental outputs is far from universally accepted.

Another structural trend in agriculture which our research suggests is having a tangible negative impact on agency is a discernible change in land tenure arrangements; most noticeably a shift from multi-generational to short-term farm business tenancies (5-10 years). Possibly not surprisingly, those tenants involved in our research expressed a reluctance to invest time and resources in substantial infrastructure or land management options (many likely to have DWPA mitigation benefits) where no long-term security of tenure is in place. Recommendations to facilitate the establishment of longer term tenancies have been made by several observers in recent times (e.g. Winter et al., 2016) but there is no guarantee this desired outcome will be realised.

Last, but by no mean least, when discussing pressures on farmer agency, there was an overriding sense amongst research respondents that a lack of financial empowerment is a major factor obstructing the take up of DWPA control measures on many farms. In simple terms, a view was expressed that greater profitability in the farming sector would enable farmers to invest further in DWPA mitigation activity than they are currently able to do. The existence of debt does not encourage farmers to actively invest energy in solving DWPA problems. There is no easy fix regarding increasing the profitability in farming, given many farmers are operating in commodity markets which have experienced falling prices in recent years. Whist government intervention in markets is very unlikely due to prevailing political and economic thinking, it is possible to conceive that the Government could facilitate the uptake of DWPA measures through fiscal incentives and enhancing environmental payments to farmers; both through public funded schemes but also through facilitating the development of private sector markets for ecosystem services. All of these options feature within current policy thinking in the UK although political uncertainties make it very difficult to predict future levels of implementation. Nonetheless, recent DTC research has suggested that farmer-preferred DWPA control measures could deliver much improved environmental performance for limited impact on annual farm incomes from agricultural land (Collins et al., 2016).

\section{Concluding remarks}

This paper has presented a structure for analysing the myriad of internal and external factors influencing DWPA mitigation behaviour within the farming community. A broad literature focussed on different determinants of farming behaviour has emerged from scholars grounded in a variety of academic disciplines. Our aim has been to propose a framework which brings the analysis of these factors under one roof in order to inform better mitigation policy. It is evident that there are still a range of items within the framework that require further attention by researchers operating within the agricultural space. These include components such as habit (individual context), the effect of institutions (the social context) and the existence of technologies, rules and regulations (material context). 
A key observation from our research is that expecting farmers to adopt mitigation measures spontaneously in response to existing incentives, advice and regulatory stimuli is unrealistic. Proactive and sustained engagement is needed, facilitated by appropriate policy support. In particular, it is likely that the scale of change needed will only be enabled by engaging the farming community in deliberative discussion over the role and purpose of food production within the wider rural landscape and the multi-functionality society increasingly requires from that landscape. Running in parallel with this process is a need for expert and trusted advice, delivered on a one-to-one basis at the individual farm level. It is only through equipping farmers with a will to change behaviour, and the confidence and ability to do so, that systemic shifts in mitigation option adoption will become manifest. In addition, compliance with environmental legislation is likely to be far higher where farmers buy-in to what they are being asked to carry out. This can only be achieved through mutual understanding which requires dialogue over an extended period of time; both at a farming network and individual farmer level.

An argument exists, therefore, for policy makers to invest resources in a properly equipped extension service with the necessary technical and social skills to engage effectively with the agricultural sector. In a time of limited public sector budgets, it is difficult to envisage such resource being forthcoming. It is worth speculating, therefore, whether resources could be made available from actors within the food supply chain, all of which ultimately depend on a sustainable land management system for their continued existence.

The future DWPA policy context is difficult to predict at present, due to the uncertainties created by the EU Referendum outcome of 23 June 2016 which is likely to see an end to the UK's membership of the European Union so called 'Brexit'. Under this scenario, the UK will no longer be a part of the Common Agricultural Policy (CAP) which is expected to result in a fundamental change in the farm support regime; specifically a move away from payments related to the area farmed towards a scheme based on the delivery of clearly delineated environmental benefits. However, the details of how such a system will work and how much it will change from current arrangements are uncertain at present. Should a fundamental shift in payments towards the environmental agenda occur, it is possible this may facilitate greater uptake of environmental measures than is currently the case. However, as this paper has argued, influencing pro-environmental behaviours may well require more than money and it may be that large sections of the farming community will feel threatened - or at best unconvinced - by the new regime and reject it. Exiting the EU also means there is no longer a need to comply with the EU Water Framework Directive, which potentially reduces the level of environmental standards UK businesses (including farms) will need to meet. Engaging with rank and file members of the farming community respectfully and with sensitivity regarding the future design of agri-environmental policy will be key; an aspect policy makers and environmentalists ignore at their peril.

\section{Acknowledgements}

The funding provided by the UK Department for Environment, Food and Rural Affairs (Defra) via projects WQ02010, WQ0211, WQ0212 and LM0304 is gratefully acknowledged. Fiona Grant assisted with the DTC farm survey in the River Avon catchment whilst in the employment of ADAS UK Ltd.

\section{References}

ADAS, 2012. FF0204 - Integrated Advice Pilot. Final Report for Defra

Ajzen, I. and Fishbein, M., 1980. Understanding attitudes and predicting social behavior. Englewood Cliffs, NJ: Prentice-Hall.

Ajzen, I., 1991. The theory of planned behavior. Organizational Behavior and Human Decision Processes, 50, 179211.

Argyris, C. and Schön, D.,1996. Organizational learning II: Theory, method and practice, Reading, Mass: Addison Wesley.

Baldassarri, D. and Diani, M., 2007. The Integrative Power of Civic Networks. American Journal of Sociology 113(3):735-80. 
Barnes, A., Willock, J., Toma, L., Hall, C., 2011. Utilising a farmer typology to understand farmer behaviour towards water quality management: Nitrate Vulnerable Zones in Scotland. Journal of Environmental Planning and Management, 54:4, 477-494, DOI

Baumgart-Getz, A., Prokopy, L.S., Floress, K., 2012. Why farmers adopt best management practice in the A metaanalysis of the adoption literature. Journal of Environmental Management 96 (2012)

Blackstock, K.L., Ingram, J., Burton, R., Brown, K.M., Slee, B., 2010. Understanding and influencing behaviour change by farmers to improve water quality. Sci. Total Environ. 408(23) 5631-8.

Burgess, P.J., Morris, J., 2009. Agricultural technology and land use futures: The UK case. Land Use Policy, Volume: 26 Special Issue: SI Supplement: 1 Pages: S222-S229

Burke, P.J., and J.E. Stets., 2009. Identity theory. New York: Oxford Press

Burke, P.J. and Reitzes, D.C., 1981. The Link Between Identity and Role Performance. Social Psychology Quarterly. Vol. 44, No. 2, pp. 83-92

Burton RJF., 2004. Seeing through the "good farmer's" eyes: towards developing an understanding of the social symbolic value of "productivist" behaviour. Sociol Rural 2004;14(2):195-216

Burton, J. and Wilson, G., 2006. Injecting social psychology theory into conceptualisations of agricultural agency: Towards a post-productivist farmer self-identity? Journal of Rural Studies 22 (2006) 95-115

Burton, R., Kuczera, C. and Schwartz, G., 2008. Exploring farmers' cultural resistance to voluntary agrienvironmental schemes. Sociologia Ruralis 48, 16-37.

Carr, S., 1988. Conservation of farm: conflicting attitudes, social pressures and behaviour. Unpublished Ph.D. Thesis, Open University.

Carr, S., and Tait, J., 1990. Farmers' attitudes to conservation. Built Environment, 16(3), 218-231

Chouinard, H.H., Paterson, T., Wandschneider, P.R., Ohler, A.M., 2008. Will farmers trade profits for stewardship? Heterogeneous motivations for farm practice selection. Land Econ. 84, 66-82.

Collins, A.L., Zhang, Y., 2016. Exceedance of modern 'background' fine-grained sediment delivery to rivers due to current agricultural land use and uptake of water pollution mitigation options across England and Wales.

Environmental Science \& Policy 61 (2016) 61-73

Collins, A.L., Zhang, Y.S., Winter, M., Inman, A., Jones, J.I., Johnes, P.J., Cleasby, W., Vrain, E., Lovett, A., Noble, L., 2016. Tackling agricultural diffuse pollution: what might uptake of farmer-preferred measures deliver for emissions to water and air. Science of the Total Environment 547, 269-281.

Colman, A., 2015. A Dictionary of Psychology. Oxford University Press. Oxford, England.

Comber, S.D.W., Smith, S., Daldorph, P., Gardner, M.J., Constantino, C., Ellor, B., 2013. Development of a chemical source apportionment decision support framework for catchment management. Environmental Science and Technology 47, 9824-9832.

Compagnone, C., and Hellec, F., 2015. Farmers' Professional Dialogue Networks and Dynamics of Change: The Case of ICP and No-Tillage Adoption in Burgundy (France). Rural Sociology 80(2), 2015, pp. 248-273

Coughenour, C.M., 2003. Innovating conservation agriculture: The case of no-till cropping. Rural Sociology 68: 278304.

Crowe, J. A., 2007. "In Search of a Happy Medium: How the Structure of Interorganizational Networks Influence [sic] Community Economic Development Strategies.” Social Networks 29(4):469-88. 
Cuttle, S.P., Newell-Price, P.J., Harris, D., Chadwick, D.R., Shepherd, M.A., Anthony, S.G.A., Macleod, C.J.A., Haygarth, P.M., Chambers, B.J., 2016. A method-centric 'User Manual' for the mitigation of diffuse water pollution from agriculture. Souil Use and Management 32 Suppl S1, 162-171

Darnton, A. \& Evans, D., 2013. The ISM Tool - a Technical Guide, Edinburgh: Scottish Government.

Darnton, A., 2008. GSR Behaviour Change Knowledge Review Reference Report: An overview of behaviour change models and their uses. Centre for Sustainable Development, University of Westminster

Demonstration Test Catchment programme phase 1 report, 2015. Summary of emerging evidence from the Demonstration Test Catchments (DTC) platform. Department of Environment, Food and Rural Affairs, London, pp 265.

Department for Environment Food \& Rural Affairs (Defra). 2010. Definitions of Terms Used in Farm Business Management, 3rd ed. Defra, London, pp. 48.

Department for Environment Food \& Rural Affairs (Defra). 2015. Policy paper 2010-2015 on water quality. Available at https://www.gov.uk/government/publications/2010-to-2015-government-policy-water-quality

Durand, P., Breur, L., Johnes, P. J., van Grinsven, H., Butturini, A., Billen, G., Garnier, J., Maberley, S., Carvalho, L., Reay, D., Curtis, C., 2011. Nitrogen turnover processes and effects in aquatic ecosystems. Chapter 7 in M. A. Sutton, C. M. Howard, J. W. Erisman, G. Billen, A. Bleeker, P. Grennfelt, H. van Grinsven, B. Grizzetti (Editors) European Nitrogen Assessment, Cambridge University Press, pp. 126-146. ISBN: 9781107006126

Dwyer, J., Mills, J., Ingram, J., Taylor, J., Burton, R., Blackstock, K., Slee, B., Brown, K., Schwarz, G., Matthews, K., Dilley, R. J., 2007. Understanding and Influencing Positive Behaviour Change in Farmers and Land Managers - a project for Defra. Final Report 30th November 2007.

Ferretti, M.P., 2007. Why Public Participation in Risk Regulation? The Case of Authorizing GMO Products in the European Union. Science as Culture 16(4):377-395.

Fielding, K.S, Terry, D.J., Masser, B.M., Bordia, P., Hogg, M.A., 2005. Explaining landholders' decisions about riparian zone management: The role of behavioural, normative, and control beliefs.

Fish, R., 2014. Influencing farmers to engage in catchment sensitive farming: an introductory guide. An introductory guide for CSFOs and their delivery partners. Report to the Environment Agency (CRPR: University of Exeter)

Gintis, H., 2000. Beyond homo economicus: Evidence from experimental economics. Ecological Economics, 35(3), 311-322.

Greene, S., Johnes, P. J., Reaney, S., Bloomfield, J. P., Freer, J. E., Macleod, C. J. M., Odoni, N., 2015. A geospatial framework to support integrated biogeochemical modelling in the United Kingdom. Environmental Monitoring and Software 68, 219-232. doi: 10.1016/j.envsoft.2015.02.012.

Hanley, N., 1990. The economics of nitrate pollution. European Review of Agricultural Economics 17, 129-151.

Herndl, C., Goodwin, J., Honeycutt, L., Wilson, G., Graham, S., Niedergeses, D., 2011. Talking sustainability: Identification and division in an Iowa community. Journal of Sustainable Agriculture 35: 436-461

House of Commons Library Briefing Paper. Number CBP 7246, November 2015. Water Framework Directive: achieving good status of waterbodies

Ingram, J., 2008. Are farmers in England equipped to meet the knowledge challenge of sustainable soil management? An analysis of farmer and advisor views. Journal of Environmental Management 86, 214-228 
Inman, A., 2011. A Review of Current Policy Tools and Funding Mechanisms Available to Address Water Pollution from Agriculture in England. Defra Strategic Evidence and Partnership Report, Defra, UK.

Johnes, P. J., Foy, R., Butterfield, D., Haygarth, P. M., 2007. Land use for Good Ecological Status: an evaluation of scenarios for water bodies in England and Wales. Soil Use and Management, 23 (1), 176-194

Kahneman, D., 2003. Maps of bounded rationality: Psychology for behavioural economics. American Economic Review, 93(5), 1449-1475.

Knowler, D. and Bradshaw, B., 2007. Farmers' adoption of conservation agriculture: A review and synthesis of recent research. Food Policy 32 (2007) 25-48

Lastra-Bravo, X.B., Hubbard, C., Garrod, G., Tolón-Becerra, A., 2015. What drives farmers' participation in EU agrienvironmental schemes? Results from a qualitative meta analysis. Environ. Sci. Policy 54, 1-9.

Lidskog, R., 1996. In Science We Trust? On the Relation Between Scientific Knowledge, Risk Consciousness and Public Trust. Acta Sociologica 39(1):31-56.

Lowe, P., Clark, J., Seymour, S., Ward, N., 1997. Moralizing the Environment: Countryside Change, Farming and Pollution. UCL Press Limited.

Lynne, G.D., Franklin Casey, C., Hodges, A., Rahmani, M., 1995. Conservation technology adoption decisions and the theory of planned behaviour. Journal of Economic Psychology, Volume 16, Issue 4, December 1995, Pages 581598

Macgregor, C.J., Warren, C.R., 2006. Adopting sustainable farm management practices within a Nitrate Vulnerable Zone in Scotland: the view from the farm. Agric Ecosyst Environ;113:108-19.

Mase, A.S., Babin, N.L., Prokopy, L.S., Genskow, K.D., 2015. Trust in Sources of Soil and Water Quality Information: Implications for Environmental Outreach and Education. Journal of the American Water Resources Association (JAWRA) 51(6):1656-1666. DOI: 10.1111/1752-1688.12349

McGonigle D.F., Harris R.C., McCamphill C., Kirk S., Dils R., Macdonald J., Bailey S., 2012. Towards a more strategic approach to research to support catchment-based policy approaches to mitigate agricultural water pollution: A UK case-study. Environmental Science and Policy 24, 4-1 4.

McGonigle, D.F., Burke, S.P., Collins, A.L., Gartner, R., Haft, M.R., Harris, R.C., Haygarth, P.M., Hedges, M.C., Hiscock, K.M., Lovett, A.A., 2014. Developing Demonstration Test Catchments as a platform for transdisciplinary land management research in England Wales. Environmental Science: Processes and Impacts 16, 1618-1628.

McGuire, J., Morton, L.W., Cast, A.D., 2013. Reconstructing the good farmer identity: shifts in farmer identities and farm management practices to improve water quality. Agric Hum Values 30:57-69

Michie, S., West, R., Campbell, R., Brown, J., Gainforth, H., 2014. ABC of Behaviour Change Theories. An Essential Resource for Researchers, Policy Makers and Practitioners. Silverback Publishing. England. Sutton, UK.

Mills, J., Gaskell, P., Reed, M., Short, C., Ingram, J., Boatman, N., Jones, N., Conyers, S., Carey, P., Lobley, M., Winter, M., 2013. Farmer Attitudes and Evaluation of Outcomes to On-Farm Environmental Management. Final Report. Countryside and Community Research Institute, Food and Environment Research Agency and Centre for Rural Policy, Exeter University.

Morris, C. and Evans, N., 2004. Agricultural turns, geographical turns: retrospect and prospect. Journal of Rural Studies 20, 95-111.

Newell-Price, Harris, D., Taylor, M., Williams, J.R., Anthony, S.G., Duethmann, D.,Gooday, R.D., Lord, E.I., Chambers, B.J., Chadwick, D.R., Misselbrook, T.H., 2011. An Inventory of Mitigation Methods and Guide to Their 
Effects on Diffuse Water Pollution, Greenhouse Gas Emissions and Ammonia Emissions from Agriculture. Report prepared as part of Defra Project WQ0106. (accessed 12.12.15).

Padel, S., 2001. Conversion to organic farming: a typical example of the diffusion of an innovation. Sociologia Ruralis $41(1), 49-61$.

Pannell, D. J., Marshall, G. R., Barr, N., Curtis, A., Vanclay, F., Wilkinson, R., 2006. Understanding and promoting adoption of conservation practices by rural landholders. Australian Journal of Experimental Agriculture, 46(11), $1407-1424$

Petty, R.E., Unnava, R.H., Strathman, A.J., 1992. Theories of attitude change. In: Robertson Thomas S, Kassirjian Harold H, editors. Handbook of Consumer Behavior. Englewood Cliffs: Prentice Hall; p. 241-68.

Price, J. \& Leviston, Z., 2014. Predicting pro-environmental agricultural practices: The social, psychological and contextual influences on land management. Journal of Rural Studies 34 (2014)

Prokopy, L.S., Floress, K., Klotthor-Weinkauf, D., Baumgart-Getz, A., 2008. Determinants of agricultural BMP adoption: Evidence from the literature, J. Soil Water Conserv. 63(5), 300-311.

Siebert, R., Toogood, M., Knierim, A., 2006. Factors Affecting European Farmers' Participation in Biodiversity Policies. Sociologia. Ruralis 46(4), 318-340.

Small, B., Brown, P., Montes de Oca Munguia, O., 2016. Values, trust, and management in New Zealand agriculture, International Journal of Agricultural Sustainability, 14:3, 282-306.

Smith, L. and Hiscock, K., 2009. Catchment management for the protection of water resources: The Ecosystem Health Report Card. Relu Policy and Practice Note No 7. Accessed 01/12/16

http://www.relu.ac.uk/news/policyandpracticenotes.htm

Stets, J.E. and Carter, M., 2011. The moral self: Applying identity theory. Social Psychology Quarterly 74: 192-215.

Stryker, S. and Burke, P.J., 2000. Past, present, and future of identity theory. Social Psychology Quarterly 63: 284297

Wang, L., Stuart, M.E., Lewis, M.A., Ward, R.S., Skirvin, D., Naden, P.S., Collins, A.L. and Ascott, M.J., 2016. The changing trend in nitrate concentrations in major aquifers due to historical nitrate loading from agricultural land across England and Wales from 1925 to 2150. Science of the Total Environment 542, 694-705.

Watson, N., Oughton, L. and Collins, K., 2013. Developing Knowledge Exchange Approaches to Secure Sustained Behaviour Changes to Deliver Multiple Environmental benefits through Sustainable Land Management. Defra Project FFG 1007. Final Project Report

Winter, M. and Lobley, M., 2016. Is there a future for the small family farm in the UK? Report to The Prince's Countryside Fund, London: Prince's Countryside Fund. ISBN 978-902746-36-7

Yeboah, F.K., Lupi, F., Kaplowitz, M.D., 2015. Agricultural landowners' willingness to participate in a filter strip program for watershed protection. Land Use Policy 49 (2015) 75-85

Zhang, Y., Collins, A.L., Murdoch, N., Lee, D..Naden, P.S., 2014. Cross sector contributions to river pollution in England and Wales: updating waterbody scale information to support policy delivery for the Water Framework Directive. Environmental Science and Policy 42, 16-32. 